\title{
Commentary: Hold 'em or fold 'em
}

\author{
John Calhoon, MD
}

\footnotetext{
From the Department of Cardiothoracic Surgery, The University of Texas Health Science Center at San Antonio, San Antonio, Tex.

Disclosures: Author has nothing to disclose with regard to commercial support.

Received for publication Sept 12, 2018; accepted for publication Sept 13, 2018; available ahead of print Nov 2 , 2018.

Address for reprints: John Calhoon, MD, Department of Surgery, The University of Texas Health Science Center at San Antonio, 7703 Floyd Curl Dr, Suite 211L, San Antonio, TX 78229 (E-mail: calhoon@uthscsa.edu). J Thorac Cardiovasc Surg 2019;157:1933

$0022-5223 / \$ 36.00$

Copyright (c) 2018 by The American Association for Thoracic Surgery

https://doi.org/10.1016/j.jtcvs.2018.09.047
}

Hui and colleagues ${ }^{1}$ have completed a very insightful study. A very wise, respected, and senior surgeon shared a sage recommendation decades ago about a potential hire who had grown to become a fine surgeon. He told me, "He was quite good, just not quite as good as he thought he was." This statement illustrates the age-old conundrum between what we think of ourselves and what others' perceptions are. As we know, perception tends to be viewed as reality. If my teachers had not perjured themselves by telling others I was ready for prime time as first a resident, and later as a young surgeon, no doubt referrals and confidence from others would not have flowed. Similarly, senior surgeons can do their best to support those who are junior, but in the end, this support only goes as far as the surgeon's results and perceptions of them take us. These days we are judged by a number of objective metrics such as Society of Thoracic Surgeons outcomes, time to complete a routine case, or our efficiency with patient discharge. We are also judged even more critically and somewhat subjectively by those who matter most. How did the nursing staff perceive your results? Were you known behind your back as Leaky Lucy or Slick Willy? Did the scrub team line up to help or did they all have something else to do when you posted an urgent case? It appears to me that we all can improve our operative results with seasoning and practice, but it remains up to each of us to know (or try to) on which operative cases we should fly solo and when it is appropriate to say no or ensure you have a senior partner involved to confirm your preoperative decision making or assist with intraoperative conduct. The study by Hui and colleagues ${ }^{1}$ provides some baseline expectations senior surgeons have toward the surgical skills of more junior surgeons, and in some ways, vice versa. In my mind, more importantly, it implores us

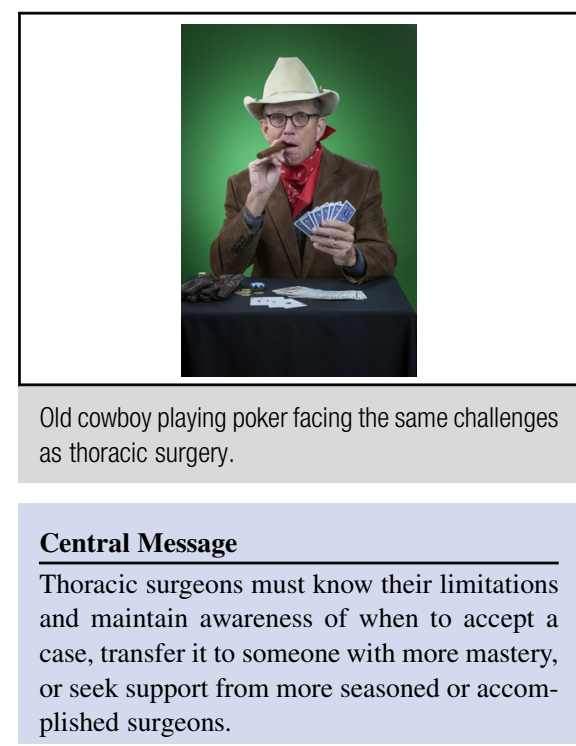

See Article page 1925.

all to think about how we can improve and how we are perceived by those for whom we work-our hospital staff, patients, and our referring physicians. It reminds each of us to be introspective and self-critical of our current skill sets. An important facet of surgical prowess that Hui and colleagues $^{1}$ did not address was when junior surgeons believed seasoned surgeons were no longer technically or mentally capable of performing at an acceptable level. Just as a more seasoned surgeon can provide advice and reasoned judgment to a junior surgeon, a senior surgeon must also be able to decide (or be judged by some set of metrics beyond just age) when the time has come to pass the reins to a more junior surgeon. Hui and colleagues ${ }^{1}$ nicely review a poorly studied and worse-yet understood problem faced throughout our careers regarding when to hold 'em or fold 'em.

Dr Hui will be joining The University of Texas Health Science Center at San Antonio effective mid-January 2019.

\section{Reference}

1. Hui DS, Lee R, Moon MR, Edwards MA, Boutrous ML, Luc JGY, et al. Disparity between recent graduates and experienced surgeons' assessment of time to operative independence. J Thorac Cardiovasc Surg. 2019;157:1925-32. 